\title{
COPD patients' oxygen uptake and heart rate on-kinetics at cycle-ergometer: correlation with their predictors of severity
}

\author{
Bruna V. Pessoa ${ }^{1}$, Thomas Beltrame ${ }^{2}$, Valéria A. Pires Di Lorenzo ${ }^{1}$, \\ Aparecida M. Catai ${ }^{2}$, Audrey Borghi-Silva ${ }^{2}$, Mauricio Jamami ${ }^{1}$
}

\begin{abstract}
Objectives: To assess whether there is a correlation between oxygen uptake $\left(\mathrm{VO}_{2}\right)$ and heart rate (HR) on-kinetics in the constant-load cycle-ergometer test (CLT) and the BODE index and its isolated variables in patients with chronic obstructive pulmonary disease (COPD). Method: Fourteen male patients between 55 and 78 years of age with moderate to severe COPD were evaluated. Each patient underwent spirometry, the six-minute walk test (6MWT), the cycle-ergometer incremental test (IT) and CLT on alternate days. The exhaled gases were collected, and the $\mathrm{VO}_{2}$ and HR on-kinetics were analyzed. The BODE index was calculated. Results: It was noted that the $\mathrm{VO}_{2}$ tau $(\tau)$ and mean response time (MRT) were significantly higher than HR $\tau$ and MRT. Moderate and strong correlations between $\tau$ and MRT of the $\mathrm{VO}_{2}$ and $\mathrm{HR}$ and the BODE index was noted ( $\mathrm{r}=0.75$ and $\mathrm{r}=0.78 ; \mathrm{r}=0.62$ and $\mathrm{r}=0.63$, respectively), and there were correlations between the $\mathrm{VO}_{2} \tau$ and MRT and the forced expiratory volume in one second $(\mathrm{FEV})(\mathrm{r}=-0.60$; $\mathrm{r}=-0.53)$ and the distance traveled at 6MWT (DT-6MWT) $(\mathrm{r}=-0.61 ; \mathrm{r}=-0.44)$ and DT-6MWT \% predicted $(\mathrm{r}=-0.62$; $\mathrm{r}=-0.46)$. The HR $\tau$ and MRT were correlated with DT-6MWT ( $\mathrm{r}=-0.59 ; \mathrm{r}=-0.58)$ and DT-6MWT \% predicted $(\mathrm{r}=-0.62$; $\mathrm{r}=-0.62$ ). Conclusion: The slowing of cycle-ergometer $\mathrm{VO}_{2}$, and especially of HR on-kinetics, may be key markers of disease severity. Furthermore, airflow obstruction and reduced exercise capacity are associated with the slowing of patients' $\mathrm{VO}_{2}$ and $\mathrm{HR}$ on-kinetics.
\end{abstract}

Keywords: COPD; oxygen uptake; kinetics; heart rate; physical therapy; disease severity index. This study was registered at ClinicalTrials.gov (NCT01529489).

\section{HOW TO CITE THIS ARTICLE}

Pessoa BV, Beltrame T, Pires Di Lorenzo VA, Catai AM, Borghi-Silva A, Jamami M. COPD patients' oxygen uptake and heart rate on-kinetics at cycle-ergometer: correlation with their predictors of severity. Braz J Phys Ther. 2013 Mar-Apr; 17(2):152-162. http://dx.doi.org/10.1590/S1413-35552012005000073

\section{Introduction}

Chronic obstructive pulmonary disease (COPD) is characterized by ventilatory, metabolic and peripheral muscle limitations and reduced exercise capacity. These limitations are associated with significant loss of body mass, reduced strength and endurance of the respiratory and peripheral muscles ${ }^{1}$ and high mortality risk $^{2}$. Additionally, exercise intolerance may be marked by the slowing of oxygen uptake $\left(\mathrm{VO}_{2}\right)$ and heart rate (HR) kinetics at exercise onset ${ }^{3,4}$ when compared to age-matched healthy elderly adults ${ }^{4,5}$.

The slowing of $\mathrm{VO}_{2}$ and HR kinetics in COPD patients is associated with hypoxemia, larger pulmonary ventilation volume, disorders of respiratory mechanics, inefficient oxygen supply across the rest-exercise transition, biomechanical breakdown of reactions stimulating peripheral mitochondrial oxygen consumption $\left(\mathrm{QO}_{2}\right)^{4-8}$, autonomic imbalance and redistribution of blood flow to peripheral and respiratory muscles ${ }^{4}$. Early recruitment of type IIb fibers and accumulation of metabolites, which increases peripheral muscle fatigue, are also part of this condition ${ }^{4,7}$.

Reduced exercise capacity has been linked to COPD patients' reduced survival. Considering the severity of the above-mentioned alterations, Celli et al. ${ }^{2}$ developed the BODE [Body Mass Index, Obstruction, Dyspnea, Exercise Capacity] index. This multidimensional index has gained ground and relevance in the scientific literature because it provides prognostic information on COPD severity, further reflecting the functional disability induced by the disease. The BODE index comprises body mass index (BMI; B), airflow obstruction (O), dyspnea (D) and exercise capacity (E). Therefore, it measures the

\footnotetext{
${ }^{1}$ Spirometry and Respiratory Therapy Laboratory, Universidade Federal de São Carlos (UFSCar), São Carlos, SP, Brazil 
primary changes found in COPD patients and has been considered their best predictor of survival ${ }^{2}$. Its isolated variables [BMI, dyspnea, forced expiratory volume in one second $\left(\mathrm{FEV}_{1}\right)$ and distance traveled in the six-minute walk test (6MWT)] are also considered evaluation parameters but fail to assess the systemic repercussions of the disease.

$\mathrm{VO}_{2}$ and $\mathrm{HR}$ kinetics have been studied using moderate-to-high intensity cycle-ergometer or treadmill constant-load tests $(\mathrm{CLT})^{9}$. It is known that the posture adopted during exercise and the effects of gravity may affect $\mathrm{VO}_{2}{ }^{10-13}$ and $\mathrm{HR}^{9,14,15}$ kinetics. The slowed $\mathrm{VO}_{2}$ on-kinetics of COPD patients was recently associated with the BODE index in constantspeed treadmill tests ${ }^{16}$. However, interestingly, the slowing of $\mathrm{VO}_{2}$ on-kinetics was associated with functional limitation by 6MWT and showed no correlation with airflow obstruction ${ }^{16}$. Considering that $\mathrm{VO}_{2}$ on-kinetics is a key index of aerobic capacity and exercise tolerance evaluation ${ }^{4,6,8,9}$ associated with the BODE index mortality predictor ${ }^{16}$, the present study aims to correlate COPD patients' $\mathrm{VO}_{2}$ and $\mathrm{HR}$ on-kinetics with the BODE index and its isolated variables at CLT. The hypothesis of the present study is that COPD patients' $\mathrm{VO}_{2}$ and HR on-kinetics are associated with the BODE index, exercise capacity and disease severity.

\section{- Method}

\section{Study subjects}

Fourteen men from 55 to 78 years of age with clinical and functional diagnosis of COPD participated in this study. All of the patients had FEV / /forced vital capacity $(\mathrm{FVC})<0.7$ and post-bronchodilator $\mathrm{FEV}_{1}$ $<80 \%$ predicted ${ }^{17}$ and were referred for treatment in the Special Unit Respiratory Physical Therapy of the Federal University of São Carlos (Unidade Especial de Fisioterapia Respiratória, Universidade Federal de São Carlos, UFSCar), São Carlos, SP, Brazil. Clinical and spirometric diagnosis of COPD at stages II, III and $\mathrm{IV}^{17}$ confirmed by pre- and post-bronchodilator spirometry performed under the supervision of a pulmonologis ${ }^{17}$, prior tobacco smoking history, no history of infections or disease exacerbation in the last month or change in medications in the four weeks preceding the survey were adopted as study inclusion criteria. Furthermore, all patients were considered sedentary for at least six months and were classified as sedentary or insufficiently active according to the International Physical Activity Questionnaire - short version (IPAQ) classification ${ }^{18}$.
Tobacco smokers, drinkers, and patients with pulmonary hypertension (mean pulmonary artery pressure $\geq 25 \mathrm{mmHg}$ detected by echocardiography), uncontrolled hypertension, hypoxemia (peripheral oxygen saturation, $\mathrm{SpO}_{2}$, below $80 \%$ at rest), or cardiovascular, metabolic, neurological, rheumatic and/or musculoskeletal disorders that would preclude participation in the study were excluded. The study was approved by the Research Ethics Committee (Comitê de Ética em Pesquisa) of UFSCar (Opinion No. 163/2010), and all patients freely signed an informed consent form according to Resolution 196/96 of the Brazilian National Health Council (Conselho Nacional de Saúde).

\section{Experimental procedures}

The study participants were subjected to a general physical examination, pulmonary function test, body composition assessment, 6MWT, symptom-limited cycle-ergometer incremental test (IT) and CLT. Data were collected from each patient on alternate days, and the tests were performed at intervals of two to four days ${ }^{19}$ to avoid negative interference with performance (presence of pain, circulating catecholamines, peripheral muscle fatigue). The tests were conducted in a room in which the temperature was controlled at $18^{\circ}$ to $22^{\circ} \mathrm{C}$ and the relative air humidity was controlled at 50 to $70 \%$; all measurements were performed at the same time of day for each patient. The patients were familiarized with the tests and the equipment on the first day of evaluation. All patients received instructions prior to performing the tests regarding the type of food to be prepared and the type of clothing and footwear to be worn for the tests; they were also instructed to avoid physical activity on the day before the tests. The patients remained at rest for approximately 15 minutes prior to performing any experimental procedure.

Pulmonary function test: This test was performed using a portable spirometer (COSMED microQuark PC - based Spirometer ${ }^{\circledR}$, Pavona di Albano, Rome, Italy), according to the American Thoracic Society/European Respiratory Society (ATS/ERS) guidelines ${ }^{20}$. The values obtained were compared with the values predicted by Knudson et al. ${ }^{21}$.

Body composition assessment: This assessment was performed by bioelectrical impedance using bipolar foot-electrodes (Tanita ${ }^{\circledR}$, model BC-553, Illinois, USA). After the and muscle mass (MM) ${ }^{22}$ analyses were performed, the BMI = body mass $(\mathrm{Kg}) /$ height $^{2}(\mathrm{~m})$ and lean muscle mass index $(\mathrm{LMMI})=\mathrm{MM}(\mathrm{Kg}) /$ height $^{2}(\mathrm{~m})^{23}$ were calculated . 
Patients with $\mathrm{LMMI}<16.0 \mathrm{Kg} / \mathrm{m}^{2}$ were considered nutritionally depleted ${ }^{23}$.

BODE index: All COPD patients underwent all of the necessary measurements to calculate the BODE index. This multidimensional index comprises the BMI, the degree of airway obstruction (predicted post-bronchodilator $\left.\mathrm{FEV}_{1} \%\right)^{17}$ and dyspnea (Medical Research Council dyspnea scale $)^{24}$ and the distance traveled at 6MWT. Patients were scored according to the results obtained for the four variables ( $0-1$ for the BMI and 0-3 for $\mathrm{FEV}_{1}$, dyspnea and distance traveled at $6 \mathrm{MWT})^{2}$. The BODE index can be divided into quartiles: quartile 1 includes scores of $0-2$, quartile 2 includes scores of 3-4, quartile 3 includes scores of 5-6, and quartile 4 includes scores of 7-10² the higher the score, the greater the patient's likelihood of mortality.

\section{Functional capacity evaluation}

Six-minute walk test (6MWT): This test was performed according to the ATS guidelines ${ }^{25}$. It was performed on a 30-meter-long flat hallway twice daily with a 30-minute interval between each session; the largest value of distance traveled was selected for analysis. The patients were instructed and encouraged to walk as fast as possible for 6 minutes, using standardized phrases every minute of the self-paced tests ${ }^{25}$. The distance traveled in the 6MWT was compared to the distance predicted using the equation of Iwama et al. ${ }^{26}$. The percentage of distance traveled was calculated using the following equation: [(distance traveled at 6MWT/predicted distance $\left.\left.{ }^{26}\right) * 100\right]$.

Symptom-limited cycle ergometer incremental test (IT): All patients underwent IT in which exhaled gases were collected $\left(\mathrm{VO}_{2000}\right.$ MedGraphics Corp. ${ }^{\circledR}$, St Paul, MN, USA) to assess the workload peak. IT was performed using a cycle ergometer with electromagnetic brakes (Ergo-FIT ${ }^{\circledR}$, model Ergo 167 Cycle, Pirmasens, Germany) and a protocol with increasing $\operatorname{steps}^{27}$. The patients were instructed to pedal at $60 \mathrm{rpm}$ with standard vocal encouragements from the same rater every two minutes. The test began with a 1-minute warm-up period at minimal cycle ergometer load $(15 \mathrm{~W})$, with 5- to $10-\mathrm{W}$ increases every 2 minutes that were individually selected to maintain the period of load increase in the 8-to-12minute range ${ }^{27}$. A 1-minute active recovery using minimal cycle ergometer load followed the peak load interruption and was followed by a 6-minute passive recovery. The patients were monitored by pulse oximetry throughout the entire test $\left(\operatorname{Nonin}^{\circledR}{ }^{\circledR}\right.$, model 2500, Minneapolis, MN, USA). HR was measured using a heart rate monitor (Polar ${ }^{\circledR}$ FS2 $\mathrm{c}^{\mathrm{TM}}$ Kempele, Finland), and dyspnea and lower limb fatigue were assessed using the CR [Category Ratio]-10 modified Borg scale ${ }^{28}$. Those measurements were combined with the blood pressure (BP) measurement. The electrocardiographic tracing was continuously recorded using an Ecafix ${ }^{\circledR}$ heart monitor (Model Active "E”, São Paulo, São Paulo, Brazil).

The criteria for IT interruption were very intense dyspnea or lower limb fatigue (Borg $>7)^{28}, \mathrm{SpO}_{2}$ $<80 \%$, reaching the maximum HR predicted for the patient's age and inability to sustain the pace previously set at $60 \mathrm{rpm}$.

The calculation of chronotropic reserve (HR:HRR reserve) was performed indirectly using the equation HRmax - HR reached in the test ${ }^{27}$, with HRmax $=220-$ age. The ventilatory demand was assessed by the ratio minute ventilation $\left(\mathrm{V}_{\mathrm{E}}\right) /$ maximum voluntary ventilation (MVV) ${ }^{27}$.

Cycle-ergometer constant load test (CLT): The patients were instructed to pedal at $60 \mathrm{rpm}$ and given standard vocal encouragements every minute. A protocol with a constant workload of $70 \%$ of the maximum intensity found in the $\mathrm{IT}^{27}$ was used to assess the patient's maximum tolerated time (tolerance limit: Tlim) and subsequent analysis of $\mathrm{VO}_{2}$ and $\mathrm{HR}$ on-kinetics. A cycle ergometer initial minimal load of $15 \mathrm{~W}$ was used for 1 minute during the warm-up and cool-down phases and in the posttest 6-minute passive recovery period. Values of $\mathrm{SpO}_{2}, \mathrm{HR}, \mathrm{BP}$, feelings of dyspnea and lower limb fatigue $^{28}$ at rest and peak exercise were recorded. The electrocardiographic tracing was monitored throughout the entire test. The physical performance and maximum tolerance reached in the test (Tlim) were recorded in addition to $\mathrm{HRR}^{27}$ and $\mathrm{V}_{\mathrm{E}} / \mathrm{MVV}^{27}$ calculation.

\section{Gas analysis}

During the tests, the exhaled gases were collected using a MedGraphics ${ }^{\circledR} \mathrm{VO}_{2000}$ model gas analyzer (St Paul, MN, USA) with a face mask coupled to a medium-flow bidirectional pneumotachograph. This system measures microsamples of exhaled gases by averaging every three breaths ${ }^{29}$. The equipment was calibrated automatically according to the manufacturer's specifications prior to each test. The data used for the analysis were $\mathrm{V}_{\mathrm{E}}\left(\mathrm{L} \mathrm{min}^{-1}\right), \mathrm{VO}_{2}$ (in $\mathrm{mL} \mathrm{min}{ }^{-1}$ and $\mathrm{mL} \mathrm{kg}^{-1} \mathrm{~min}^{-1}$ ), carbon dioxide output $\left(\mathrm{VCO}_{2}\right)$, respiratory rate (RR) and tidal volume $(\mathrm{TV})^{27}$. The acceptable interday reliability for $\mathrm{V}_{\mathrm{E}}$ (VC $7.3-8.8 \%$ ), $\mathrm{VO}_{2}$, and $\mathrm{VCO}_{2}$ (VC: $5.3-6.0 \%$ ) has been evaluated in previous studies ${ }^{29}$. The highest 
and most consistent value of the last 30 seconds of the stage was used to assess the value of metabolic, ventilatory and cardiovascular variables, dyspnea and lower limb fatigue at peak IT or CLT Tlim.

\section{On-kinetics analysis}

The $\mathrm{VO}_{2}$ and $\mathrm{HR}$ raw data were transferred into SigmaPlot 11.0 software (Systat Software, San Jose, CA, USA) for analysis. Phase I kinetics (cardiodynamic) were not excluded because there was a previous warm-up that, combined with the ergospirometer used, reduced the possibility of that phase affecting the kinetic evaluation ${ }^{30}$. The restto-exercise transition response (first 180 seconds) was subjected to a monoexponential fit, $\mathrm{f}_{(\mathrm{t})}=\mathrm{a}_{0}+\mathrm{a}$ $\left(1-\mathrm{e}^{-(\mathrm{t}-\mathrm{TD}) /} \tau\right)$, where $\mathrm{f}_{(\mathrm{t})}$ represents $\mathrm{VO}_{2}$ or HR at any time ${ }_{(t)} ; \mathrm{a}_{0}$ is the basal value corresponding to the mean value of the final minute of the warm-up period; " $a$ " is the amplitude, that is, the magnitude of the steadystate response; $\tau$ is the curve time constant, which is the time required to reach $63 \%$ of the steady-state response (that is, the adaptation rate); and TD is the time delay for the onset of the $\mathrm{VO}_{2}$ or $\mathrm{HR}$ response. The mean response time was also calculated (MRT, $\tau+\mathrm{TD})^{31}$.

A nonlinear algorithm using least squares to assess the best-fit parameters was used for the kinetics study ${ }^{32,33}$. The $a_{0}$ and $a_{1}$ parameters describe the parameters related to the $\mathrm{Y}$-axis main component ( $\mathrm{VO}_{2}$ and $\mathrm{HR}$ ), while $\tau$ and TD describe the parameters related to the $\mathrm{X}$-axis (time). Only functions with $r>95 \%$ were included in the final analysis to ensure the quality of the regressions ${ }^{34}$.

\section{Statistical analysis}

The statistical software SPSS 18.0 was used for data analysis. Data normality was assessed by applying the Shapiro-Wilk test, which indicated that the study sample had normal distribution. The values were expressed as the mean and standard deviation or median (interquartile range). The paired t-test was used to analyze the parameters of $\mathrm{VO}_{2}$ and $\mathrm{HR}$ on-kinetics at CLT, and Pearson and Spearman's correlation coefficients was used. The significance level was set at $\mathrm{p}<0.05$.

\section{Results}

\section{Study subjects}

Table 1 shows the studied patients' demographic, anthropometric, spirometric, 6MWT, dyspnea, and BODE index characteristics. Eight COPD patients were graded as GOLD stage $\mathrm{II}^{17}$, five patients were considered GOLD stage III $^{17}$, and one was considered GOLD stage $\mathrm{IV}^{17}$. Four of the 14 patients with COPD used short-acting bronchodilators, and eight used long-acting bronchodilators. Two patients from that sample combined the used of oral corticosteroids, and two others combined short- and long-acting bronchodilators. The patients with bronchodilators used the medication during the evening prior to the test, so most of them performed the tests after more than eight post-bronchodilator hours.

The study patient's metabolic, ventilatory and cardiovascular responses, the maximum power output (watts) at IT and the maximum tolerance reached (minutes) at CLT are shown in Table 2.

\section{Oxygen uptake and heart rate on-kinetics}

Table 3 shows the studied patients' values of $\mathrm{VO}_{2}$ and $\mathrm{HR}$ on-kinetics at CLT. The $\mathrm{VO}_{2} \tau$ and MRT were significantly higher than the HR $\tau$ and MRT.

\section{Correlations}

Figures $1 \mathrm{~A}, 1 \mathrm{~B}, 1 \mathrm{C}, 1 \mathrm{D}, 1 \mathrm{E}$ and $1 \mathrm{~F}$ show the correlations between the COPD patients' $\mathrm{VO}_{2} \tau$ and MRT and the BODE index, $\mathrm{FEV}_{1}$ and distance traveled at 6MWT. Figures 2A, 2B, 2C and 2D show the correlations between the COPD patients' HR $\tau$ and MRT and the BODE index and distance traveled at 6MWT.

Strongly significant positive correlations were found in the CLT between the BODE index and the $\mathrm{VO}_{2} \tau$ and MRT $(r=0.75$ and $r=0.78$, respectively), and moderately negative correlations were found between the $\mathrm{VO}_{2} \tau$ and MRT and the $\mathrm{FEV}_{1}(\mathrm{r}=-0.60$ and $r=-0.53$, respectively), the distance traveled at 6MWT ( $r=-0.61$ and $r=-0.44$, respectively) and the predicted $\%$ distance traveled $(r=-0.62$ and $r=-0.46$, respectively). Furthermore, moderately statistically significant positive correlations were found in the CLT between the BODE index and the HR $\tau$ and MRT $(r=0.62$ and $r=0.63$, respectively), while moderately significant negative correlations of the HR $\tau$ and MRT with the distance traveled at 6MWT $(r=-0.59$ and $r=-0.58$, respectively) and the predicted $\%$ distance traveled $(r=-0.62$ and $r=-0.62$, respectively) were found.

\section{Discussion}

The main results of this study show positive correlations between the $\tau$ and MRT of the $\mathrm{VO}_{2}$ and HR at CLT and the BODE index and negative 
Table 1. COPD patients' demographic, anthropometric, spirometric, six-minute walk test, MRC scale and BODE index characteristics.

Variables

COPD Patients $(n=14)$

Demographic and Anthropometric

Age (years)

Body Mass (kg)

Height $(\mathrm{cm})$

BMI $\left(\mathrm{kg} / \mathrm{m}^{2}\right)$

Lean Muscle Mass (kg)

LMMI $\left(\mathrm{kg} / \mathrm{m}^{2}\right)$

$\mathrm{FEV}_{1}(\mathrm{~L})$

$\mathrm{FEV}_{1}$ (\%pred)

FVC (L)

FVC (\%pred)

$\mathrm{FEV}_{1} / \mathrm{FVC}(\%)$

$\mathrm{FEV}_{1} / \mathrm{FVC}$ (\%pred)

$\operatorname{MVV}(\mathrm{L} / \mathrm{min})$

MVV (\%pred)

Distance Traveled (m)

Distance Traveled (\%predicted)

$$
\text { MRC - } 1
$$

MRC - 2

BODE Index

BODE Index - Quartile 1

BODE Index - Quartile 2

BODE Index - Quartile 3

$$
\begin{gathered}
68.0 \pm 6.5 \\
69.5 \pm 11.7 \\
167.1 \pm 7.7 \\
24.7 \pm 2.7 \\
47.5 \pm 7.4 \\
16.9 \pm 1.6
\end{gathered}
$$

\section{Spirometric}

$$
1.7 \pm 0.7
$$

$58.7 \pm 17.4$

$3.0 \pm 1.0$

$87.9 \pm 24.5$

$54.5 \pm 12.7$

$61.7 \pm 11.4$

$57.0 \pm 26.1$

Six-minute walk test (6MWT)

$$
\begin{gathered}
435.0 \pm 85.7 \\
77.9 \pm 15.5 \\
1 \text { patient } \\
13 \text { patients } \\
2.0(1.0-3.0) \\
9 \text { patients } \\
4 \text { patients } \\
1 \text { patient }
\end{gathered}
$$

$65.2 \pm 32.8$

Data are expressed as the mean \pm standard deviation; median (interquartile range). $\mathrm{COPD}=$ chronic obstructive pulmonary disease; $\mathrm{BMI}=$ body mass index; $\mathrm{LMMI}=$ lean muscle mass index $\mathrm{FEV}_{1=}$ forced expiratory volume in one second; $\mathrm{FVC}=$ forced vital capacity; $\mathrm{MVV}=$ maximum voluntary ventilation; $\mathrm{MRC}=$ Medical Research Council scale .

correlations between the $\mathrm{VO}_{2} \tau$ and MRT at CLT and the $\mathrm{FEV}_{1}$ and exercise capacity at $6 \mathrm{MWT}$. Regarding HR on-kinetics, only moderately negative correlations were found between $\tau$ and MRT and exercise capacity at $6 \mathrm{MWT}$.

\section{Oxygen uptake and heart rate on-kinetics}

The COPD patients' $\mathrm{VO}_{2} \tau$ and MRT were significantly slower than the HR $\tau$ and MRT at CLT, most likely indicating the presence of peripheral limitation in the study population. A faster rise in HR on-kinetics may show a better fit of that physiological variable to physical activity in COPD patients.

\section{$\mathrm{VO}_{2}$ and HR on-kinetics and its relationship to the BODE index and its determinants}

The BODE index has been suggested as a key mortality-predictive index in COPD and may indicate the degree of systemic and functional impairment caused by the disease ${ }^{2}$. It is known that the on-kinetics of $\mathrm{VO}_{2}$ and, as was more recently shown, of HR are slowed in the presence of $\mathrm{COPD}^{3-7,16,35}$ and that these variables enable the inference of such patients' 
compromised exercise performance ${ }^{3,4}$. It was recently suggested that the BODE index is associated with COPD patients' slowed $\mathrm{VO}_{2}$ on-kinetics ${ }^{16}$. However, the authors infer that one of the limitations underlying the lack of results regarding HR on-kinetics could be the type of ergometer used (treadmill), which unlike the present study, in which a cycle ergometer was used, did not allow precise control of the external load during the physical exercise. It is also noteworthy that exercises performed on a treadmill ${ }^{9,11-14}$ provide greater recruitment of muscle mass, show distinct patterns of motor unit recruitment and result in changes in perfusion pressure ${ }^{9}$ and muscle blood flow compared to exercises performed on a cycle ergometer. It is noteworthy that the results of the current study showed moderate to strong correlations between $\mathrm{VO}_{2}$ and $\mathrm{HR}$ on-kinetics in tests performed on a cycle ergometer after assessing the BODE index, including only COPD patients in the sample and using the first 180 seconds of the rest-to-exercise transition response, unlike the study by Borghi-Silva et al. ${ }^{16}$, which used 360 seconds of exercise performed on a treadmill.

Based on the discussion presented above, the slowed $\mathrm{VO}_{2}$ and $\mathrm{HR}$ on-kinetics at cycle-ergometer, especially the latter, may be key markers of COPD severity. Studies have shown that the BODE index accurately reflects patients' limitations in the

Table 2. Study subjects' metabolic, ventilatory, cardiovascular and subjective responses and physical capacity at the symptom-limited incremental exercise test (IT) and constant-load cycle-ergometer test (CLT).

COPD Patients $(n=14)$

Physical capacity

Metabolic Variables

$$
\begin{aligned}
& \mathrm{VO}_{2} \text { peak }(\mathrm{L} / \mathrm{min}) \\
& \mathrm{VO}_{2} \text { peak (\% pred) }
\end{aligned}
$$

Ventilatory Variable

$$
\begin{aligned}
& \mathrm{V}_{\mathrm{E}} \text { peak }(\mathrm{L} / \mathrm{min}) \\
& \mathrm{V}_{\mathrm{E}} / \mathrm{MVV} \\
& \mathrm{SpO}_{2}(\%)
\end{aligned}
$$

\section{Symptom-limited incremental exercise test (TI)}

$$
58.6 \pm 18.4
$$

$$
1.23 \pm 0.41
$$$$
72.2 \pm 21.1
$$

$39.1 \pm 7.9$

$36.5 \pm 20.3$

$0.70 \pm 0.17$

\begin{tabular}{|c|c|c|}
\hline HR peak (beats.min ${ }^{-1}$ ) & $123.1 \pm 15.4$ & $124.4 \pm 14.9$ \\
\hline HRR (beats. $\min ^{-1}$ ) & $31.1 \pm 17.0$ & $34.5 \pm 16.5$ \\
\hline
\end{tabular}

$93.3 \pm 2.8$

$$
17.0 \pm 9.7
$$

$$
\begin{aligned}
& 1.08 \pm 0.40 \\
& 62.7 \pm 19.9
\end{aligned}
$$

Constant-load cycle- ergometer test (CLT)

\section{Cardiovascular Variables}

\section{Subjective Variables}
Dyspnea peak
$4(1-6)$
$2(1-6)$
LL fatigue peak
$4(1-7)$
$2(0.5-6)$

$\mathrm{VO}_{2=}$ oxygen uptake; $\mathrm{VE}=$ pulmonary ventilation $; \mathrm{V}_{\mathrm{E}} / \mathrm{MVV}=$ airflow demand; $\mathrm{HR}=$ heart rate; HRR = heart rate reserve; $\mathrm{SpO}_{2=}$ peripheral oxygen saturation; $\mathrm{LL}=$ lower limbs. Physical Capacity refers to the maximum power output (watts) at IT and limit of tolerance (Tlim; minutes) reached at CLT.

Table 3. Study patients' oxygen uptake $\left(\mathrm{VO}_{2}\right)$ and heart rate (HR) on-kinetics parameters at the constant-load cycle-ergometer test (CLT).

\section{CLT $\quad \mathrm{VO}_{2}$ on-kinetics}

Baseline (BL)

Amplitude (a)

Tau $(\tau, s)$

Time Delay (TD, s)

$\operatorname{MRT}(\tau+\mathrm{TD}, \mathrm{s})$

$$
\begin{gathered}
392.4 \pm 265.3 \\
558.9 \pm 175.3 \\
60.6 \pm 14.4 \\
2.8 \pm 6.1
\end{gathered}
$$$$
63.4 \pm 14.1
$$

\section{HR on-kinetics}

$86.6 \pm 11.9$

$14.1 \pm 4.3$

$38.5 \pm 20.6^{*}$

$0.6 \pm 1.4$

$39.1 \pm 20.4^{*}$

Data are expressed as the mean \pm standard deviation. Baseline and Amplitude: $\mathrm{L} / \mathrm{min}$ for $\mathrm{VO}_{2}$ and beats. $\mathrm{min}^{-1}$ for $\mathrm{HR}$, respectively. Paired $\mathrm{t}$-test $(\mathrm{p}<0.001): *=\tau$ and MRT of $\mathrm{VO}_{2} \neq \tau$ and MRT of $\mathrm{HR}$. $\mathrm{VO}_{2=}$ oxygen uptake; $\mathrm{HR}=$ heart rate; $\mathrm{a}=$ steady-state response magnitude; $\tau=$ curve time constant, that is, time required to reach $63 \%$ of the steady-state response (adaptation rate); TD = response onset time delay; MRT $=$ mean response time $(\tau+\mathrm{TD})$. 

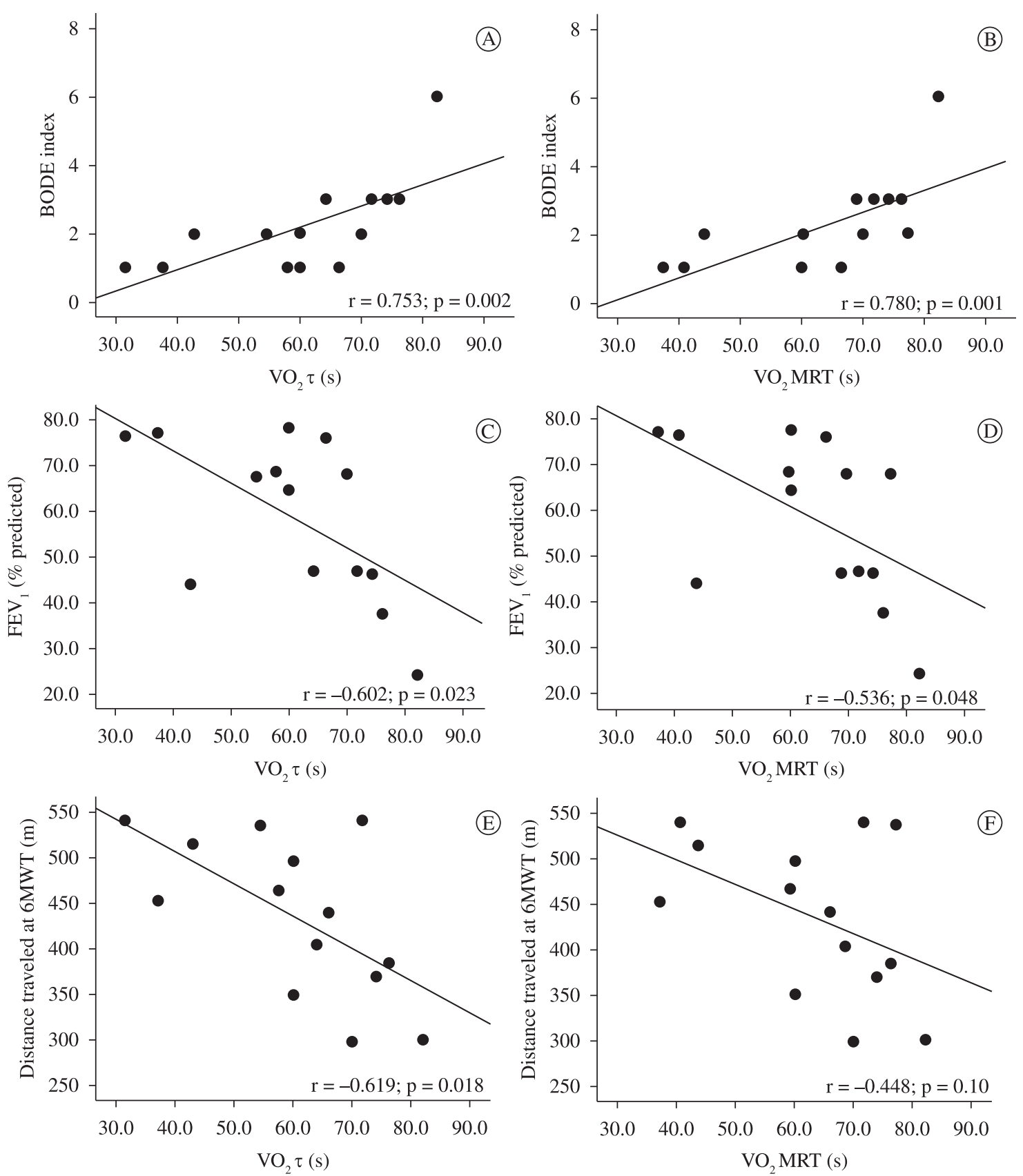

Figure 1. Correlation between oxygen uptake $\left(\mathrm{VO}_{2}\right)$ time constant $(\tau)$ and mean response time (MRT) and the BODE [Body Mass Index, Obstruction, Dyspnea, Exercise Capacity] Index, forced expiratory volume in one second $\left(\mathrm{FEV}_{1}\right)$ and distance traveled at the six-minute walk test (6MWT) of chronic obstructive pulmonary disease (COPD) patients.

activities of daily life according to the London Chest Activity Daily Living Score ${ }^{36}$. Furthermore, it reflects upper-limb peripheral muscle weakness evaluated by the manual dynamometer ${ }^{37}$ and exercise capacity assessed by the 2-minute Sit-to-Stand Test test and the 6MWT on a treadmill ${ }^{37}$, measures that may also reflect the level of limitation of the physical activities of daily life according to the time spent per day in various activities and body positions, including walking, standing, and the intensity of movement measured when the patient is walking ${ }^{38}$.

Additionally, there are moderate correlations between $\mathrm{FEV}_{1}$ and distance traveled at 6MWT with $\mathrm{VO}_{2}$ on-kinetics, unlike the results of the study by Borghi-Silva et al. ${ }^{16}$, in which only correlations with the 6MWT were found. The differences in the results 

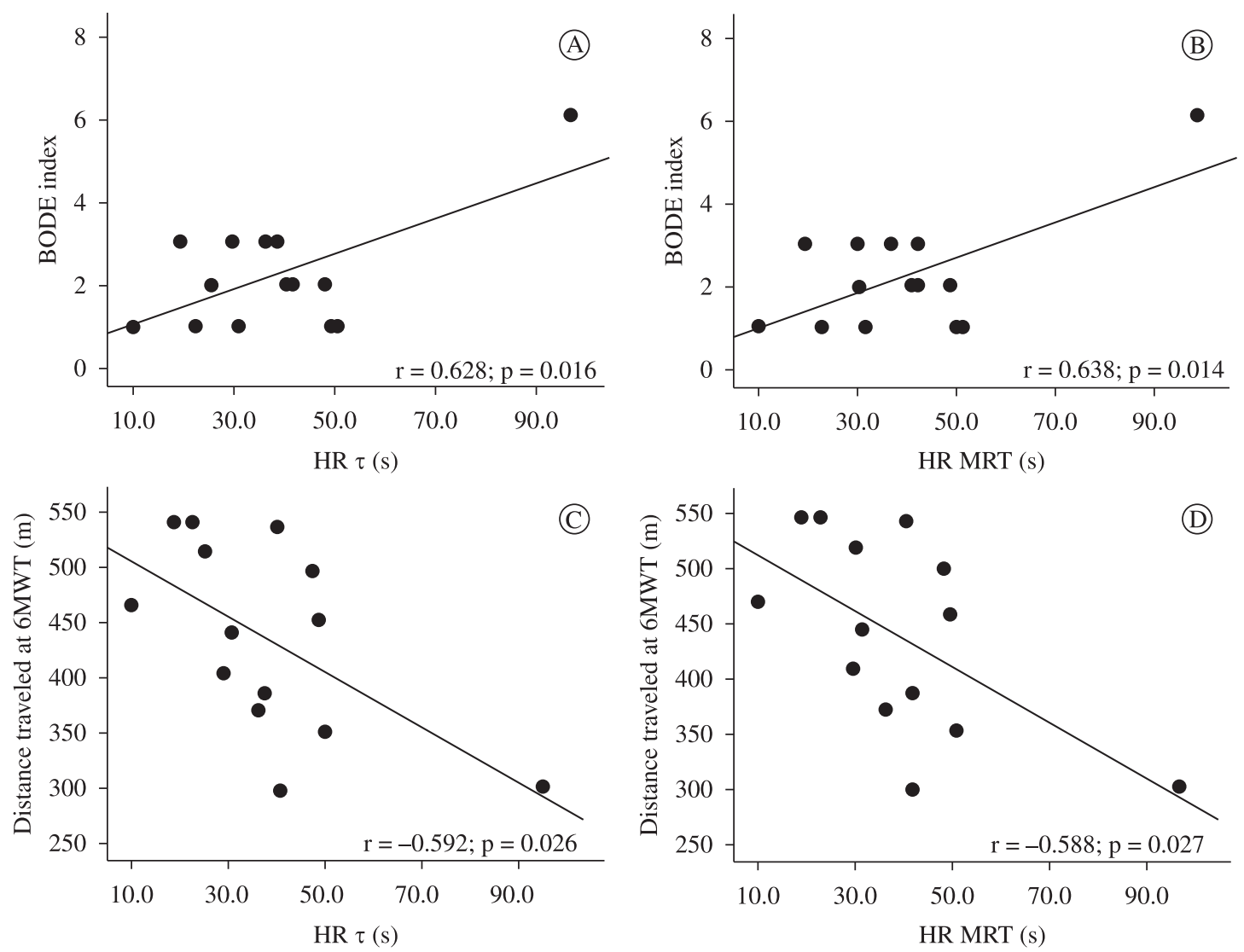

Figure 2. Correlation between the heart rate (HR) time constant $(\tau)$ and mean response time (MRT) and the HR BODE [Body Mass Index, Obstruction, Dyspnea, Exercise Capacity] Index and distance traveled at the six-minute walk test (6MWT) of chronic obstructive pulmonary disease (COPD) patients.

can most likely be explained by the use of different types of ergometers in the two studies ${ }^{9,11-14}$.

Moderate negative correlations were found between $\mathrm{VO}_{2} \tau$ and MRT and $\mathrm{FEV}_{1}$, suggesting that the slowing of $\mathrm{VO}_{2}$ on-kinetics is reflected by the level of airway obstruction, although the same cannot be said regarding $\mathrm{HR}$ on-kinetics. $\mathrm{FEV}_{1}$ is one of the variables composing the BODE index and has been considered a key prognostic marker of mortality in $\mathrm{COPD}^{39}$, although studies show that $\mathrm{FEV}_{1}$ alone does not represent systemic manifestations of the disease $\mathrm{e}^{40,41}$.

The COPD patients' $\mathrm{VO}_{2}$ and $\mathrm{HR} \tau$ and MRT showed moderate negative correlation with distance traveled (m) and predicted (\%) at 6MWT. These results provide further data on exercise performance assessed by on-kinetics as a prognostic marker in COPD patients. In contrast, there were no statistically significant correlations between $\mathrm{VO}_{2}$ and $\mathrm{HR} \tau$ and MRT with BMI and BMI, suggesting that this parameter do not quantify the slowing of $\mathrm{VO}_{2}$ and $\mathrm{HR}$ on-kinetics. Other authors also claim to have found no relationship between BMI and peripheral muscle impairment, exercise capacity, muscle mass, level of physical activity in daily life or limitations in dailylife activities ${ }^{36,42-46}$. The absence of correlation can be attributed to the low levels of disease severity in the COPD patients studied (nine patients in quartile 1 , four patients in quartile 2 and only one patient in quartile 3).

\section{Study limitations}

One of the limitations of this study is the small number of participants; a larger number of participants would strengthen the results. However, despite the relatively small sample number, moderateto-strong correlations were found in the present study. The method of HR (mean taken every three beats) and $\mathrm{VO}_{2}$ (mean taken every three breaths) data collection also represents a study limitation. However, some authors ${ }^{47-49}$ report that $\mathrm{HR}$ and $\mathrm{VO}_{2}$ data obtained using ergospirometric systems like the system used in the present study are similar to those obtained using the breath-to-breath systems 
that are currently in use. Finally, a monoexponential model was applied in the present study to analyze the moderate-to-high intensity exercise on-kinetics, even at $70 \% \mathrm{VO}_{2}$ peak exercise. However, the time used in the present study ( 3 minutes) excluded the possibility of slow component onset, which was also used in previous studies ${ }^{4,7}$.

\section{Conclusions}

The observed slowed-ergometer on-kinetics of $\mathrm{VO}_{2}$, and especially of $\mathrm{HR}$, in COPD patients may be key markers of disease severity. Furthermore, the airflow obstruction and reduced exercise capacity observed in COPD patients are associated with the slowing of $\mathrm{VO}_{2}$ and $\mathrm{HR}$ on-kinetics. Further studies evaluating kinetic effects as markers of systemic damage in COPD patient populations, the effects of different treatments and the use of different ergometers are required.

\section{Acknowledgments}

Grateful acknowledgement is made of our colleagues in the Laboratory of Spirometry and Respiratory Physical Therapy (Laboratório de Espirometria e Fisioterapia Respiratória) and the Cardiopulmonary physical therapy Laboratory (Laboratório de Fisioterapia Cardiopulmonar) for their friendly cooperation and of the study patients for their effort and cooperation during this research. We would also like to acknowledge the São Paulo Research Foundation (Fundação de Amparo à Pesquisa do Estado de São Paulo, FAPESP), which provided funding (2009/01842-0), and the Capes [Higher Education Coordination Agency] and CNPq [National Council for Scientific and Technological Development] for granting a scholarship.

\section{References}

1. Dourado VZ, Tanni SE, Vale SA, Faganello MM, Sanchez FF, Godoy I. Systemic manifestations in chronic obstructive pulmonary disease. J Bras Pneumol. 2006;32(2):161-71.

2. Celli BR, Cote CG, Marin JM, Casanova C, Montes de Oca M, Mendez RA, et al. The body-mass index, airflow obstruction, dyspnea, and exercise capacity index in chronic obstructive pulmonary disease. N Engl J Med. 2004;350(10):1005-12. http://dx.doi.org/10.1056/ NEJMoa021322

3. Puente-Maestu L, Sánz ML, Sánz P, Nuñez A, González F, Whipp BJ. Reproducibility of the parameters of the on-transient cardiopulmonary responses during moderate exercise in patients with chronic obstructive pulmonary disease. Eur J Appl Physiol. 2001;85:434-441. http:// dx.doi.org/10.1007/s004210100486

4. Chiappa GR, Borghi-Silva A, Ferreira LF, Carrascosa C, Oliveira CC, Maia J, et al. Kinetics of muscle deoxygenation are accelerated at the onset of heavy-intensity exercise in patients with COPD: relationship to central cardiovascular dynamics. J Appl Physiol. 2008;104:1341-50. http:// dx.doi.org/10.1152/japplphysiol.01364.2007

5. Laveneziana P, Valli G, Onorati P, Paoletti P, Ferrazza AM, Palange P. Effect of heliox on heart rate kinetics and dynamic hyperinflation during high-intensity exercise in COPD. Eur J Appl Physiol. 2011;111:225-234. http:// dx.doi.org/10.1007/s00421-010-1643-z

6. Somfay A, Pórszász J, Lee SM, Casaburi R. Effect of hyperoxia on gas exchange and lactate kinetics following exercise onset in nonhypoxemic COPD patients. Chest. 2002;121:393-400. http://dx.doi.org/10.1378/ chest.121.2.393

7. Chiappa GR, Queiroga Junior F, Meda E, Ferreira LF, Diefenthaeler F, Nunes M, et al. Heliox improves oxygen delivery and utilization during dynamic exercise in patients with chronic obstructive pulmonary disease. Am J Respir Crit Care Med. 2009;179(11):1004-10. http://dx.doi. org/10.1164/rccm.200811-1793OC

8. Poole DC, Ferreira LF, Behnke BJ, Barstow TJ, Jones AM. The final frontier: oxygen flux into muscle at exercise onset. Exerc Sport Sci Rev. 2007;35:166-173. http:// dx.doi.org/10.1097/jes.0b013e318156e4ac

9. Jones AM, Burnley M. Chapter 4: Effect of exercise modality on $\mathrm{VO}_{2}$ kinetics. In: Jones AM, Poole DC. Oxygen Uptake Kinetics in Sport, Exercise and Medicine. London, New York: Routledge; 2005. p. 95-114.

10. Williamson JW, Raven PB, Whipp BJ. Unaltered oxygen uptake kinetics at exercise onset with lower body positive pressure. Exp Physiol. 1996;81:695-705.

11. Koga S, Shiojiri T, Shibasaki M, Kondo N, Fukuba Y, Barstow TJ. Kinetics of oxygen uptake during supine and upright heavy exercise. J Appl Physiol. 1999;87:253-60.

12. Hughson RL, Cochrane JE, Butler GC. Faster $\mathrm{O}_{2}$ uptake kinetics at onset of supine exercise with than without lower body negative pressure. J Appl Physiol. 1993;75:1962-7.

13. Rossister HB, Ward SA, Kowalchuk JM, Howe FA, Griffiths JR, Whipp BJ. Effects of prior exercise on oxygen uptake and phosphocreatine kinetics during high-intensity knee - extension exercise in humans. J Physiol. 2001;537(Pt 1):291-303. http://dx.doi. org/10.1111/j.1469-7793.2001.0291k.x

14. Hughson RL. Chapter 8: Regulation of $\mathrm{VO}_{2}$ on-kinetics by $\mathrm{O}_{2}$ delivery. In: Jones AM, Poole DC. Oxygen Uptake Kinetics in Sport, Exercise and Medicine. London, New York: Routledge; 2005. p. 185-211.

15. Schneider DA, Wing AN, Morris NR. Oxygen uptake and heart rate kinetics during heavy exercise: a comparison between arm cranking and leg cycling. Eur J Appl Physiol. 2002;88:100-6. http://dx.doi.org/10.1007/ s00421-002-0690-5

16. Borghi-Silva A, Beltrame T, Reis MS, Sampaio LMM, Catai AM, Arena R, et al. Relationship between oxygen consumption kinetics and BODE Index in COPD patients. 
Int J Chron Obstruct Pulmon Dis. 2012;7:711-718. http:// dx.doi.org/10.2147/COPD.S35637

17. Global Initiative for Chronic Obstructive Lung Disease - GOLD. Global Strategy for the diagnosis, management, and prevention of chronic obstructive pulmonary disease. 2010.

18. Matsudo S, Araújo T, Marsudo V, Andrade D, Andrade E, Oliveira LC, et al. Questionário internacional de atividade fisica (IPAQ). Estudo de validade e reprodutibilidade no Brasil. Rev Bras Ativ Fís Saúde. 2001;6(2):5-18.

19. Montes de Oca M, Ortega Balza M, Lezama J, López JM. Chronic obstructive pulmonary disease: evaluation of exercise tolerance using three different exercise tests. Arch Bronconeumol. 2001;37(2):69-74.

20. Miller MR, Crapo R, Hankinson J, Brusasco V, Burgos F, Casaburi R, et al. ATS/ERS Task Force: Standardisation of Lung Function Testing. Eur Respir J. 2005;26:319-38. http://dx.doi.org/10.1183/09031936.05.00034805

21. Knudson RJ, Lebowitz MD, Holberg CJ, Burrows B. Changes in the normal maximal expiratory flowvolume curve with growth and aging. Am Rev Respir Dis. 1983;127:725-734.

22. Mendes CCT, Raele R. Avaliação corporal por bioimpedância. Rev Nutr Pauta. 1997;24:12-4.

23. Vermeeren MAP, Creutzberg EC, Schols AMWJ, Postma DS, Pieters WR, Roldaan AC, et al. Prevalence of nutritional depletion in a large out-patient population of patients with COPD. Resp Med. 2006;100(8):1349-55. http://dx.doi.org/10.1016/j.rmed.2005.11.023

24. Kovelis D, Segretti NO, Probst VS, Lareau SC, Brunetto AF, Pitta F. Validação do Modified Pulmonary Functional Status and Dyspnea Questionnaire e da escala do Medical Research Council para o uso em pacientes com doença pulmonar obstrutiva crônica no Brasil. J Bras Pneumol. 2008;34(12):1008-1018. http://dx.doi. org/10.1590/S1806-37132008001200005

25. American Thoracic Society - ATS. ATS Statement: Guidelines for the six-minute walk test. Am J Respir Crit Care Med. 2002;166:111-7.

26. Iwama AM, Andrade GN, Shima P, Tanni SE, Godoy I, Dourado VZ. The six-minute walk test and body weightwalk distance product in healthy Brazilian subjects. Braz J Med Biol Res. 2009;42(11):1080-5. http://dx.doi. org/10.1590/S0100-879X2009005000032

27. Neder JR, Nery LE. Fisiologia Clínica do Exercício. São Paulo, Artes Médicas; 2003.

28. Borg GA. Psychophysical bases of perceived exertion. Med Sci Sports Exerc. 1982;14:377-81. http://dx.doi. org/10.1249/00005768-198205000-00012

29. Crouter SE, Antczak A, Hudak JR, DellaValle DM, Haas JD. Accuracy and reliability of the ParvoMedics TrueOne 2400 and MedGraphics $\mathrm{VO}_{2000}$ metabolic systems. Eur J Appl Physiol. 2006;98:139-51. http:// dx.doi.org/10.1007/s00421-006-0255-0

30. Whipp BJ, Ward SA, Lamarra N, Davis JA, Wasserman K. Parameters of ventilatory and gas exchange dynamics during exercise. J Appl Physiol. 1982;52;1506-1513.

31. Bell C, Paterson DH, Kowalchuk JM, Padilla J, Cunningham DA. A comparison of modeling techniques used to characterize oxygen uptake kinetics during the on-transient of exercise. Experimental Physiology. 2001;86(5):667-76. http://dx.doi.org/10.1113/eph8602150

32. Engelen M, Porszasz J, Riley M, Wasserman K, Maehara $\mathrm{K}$, Barstow TJ. Effects of hypoxic hypoxia on $\mathrm{O}_{2}$ uptake and heart rate kinetics during heavy exercise. J Appl Physiol. 1996;81:2500-8.

33. Motulsky HJ, Ransnas LA. Fitting curves to data using nonlinear regression: a practical and nonmathematical review. FASEB J. 1987 Nov;1(5):365-374.

34. Rossister HB, Ward SA, Kowalchuk JM, Howe FA, Griffiths JR, Whipp BJ. Dynamic asymmetry of phosphocreatine concentration and $\mathrm{O}_{2}$ uptake between the on-and-off transients of moderate and high intensity exercise in humans. J Physiol. 2002; 541:991-1002. http:// dx.doi.org/10.1113/jphysiol.2001.012910

35. Poole DC, Hirai DM, Copp SW, Musch TI. Muscle oxygen transport and utilization in heart failure: implications for exercise (in)tolerance. Am J Physiol Heart Circ Physiol. 2012;302(5):H1050-H1063. http://dx.doi. org/10.1152/ajpheart.00943.2011

36. Simon KM, Carpes MF, Corrêa KS, Santos K, Karloh M, Mayer AF. Relationship between daily living activities (ADL) limitation and the BODE index in patients with chronic obstructive pulmonary disease. Rev Bras Fisioter. 2011;15:212-8. http://dx.doi.org/10.1590/ S1413-35552011000300007

37. Regueiro EMG, Pires Di Lorenzo VA, Basso RP, Pessoa BV, Jamami M, Costa D. Relationship of BODE Index to functional tests in chronic obstructive pulmonary disease. Clinics. 2009;64:983-8. http://dx.doi.org/10.1590/ S1807-59322009001000008

38. Mantoani LC, Hernandes NA, Guimarães MM, Vitorasso RL, Probst VS, Pitta F. Does the BODE index reflect the level of physical activity in daily life in patients with COPD? Rev Bras Fisioter. 2011;15:131-7. http://dx.doi. org/10.1590/S1413-35552011000200008

39. Oga T, Nishimura K, Tsukino M, Sato S, Hajiro T. Analysis of the factors related to mortality in chronic obstructive pulmonary disease: role of exercise capacity and health status. Am J Respir Crit Care Med. 2003;167(4):544-9. http://dx.doi.org/10.1164/rccm.200206-583OC

40. Cestaro EJ, Pires Di Lorenzo VA, Marino DM, Walsh I, Ruas G, Jamami M, et al. Fatores que influenciam a capacidade física de pacientes com doença pulmonar obstrutiva crônica. Fisioter Pesqui. 2010;17(4):332-6.

41. Freitas CG, Pereira CAC, Viegas CAA. Capacidade inspiratória, limitação ao exercício, e preditores de gravidade e prognóstico, em doença pulmonar obstrutiva crônica. J Bras Pneumol. 2007;33(4):389-96. http://dx.doi. org/10.1590/S1806-37132007000400007

42. Pitta F, Troosters T, Spruit MA, Probst VS, Decramer M, Gosselink R. Characteristics of physical activities in daily life in chronic obstructive pulmonary disease. Am J Respir Crit Care Med. 2005;171(9):972-7. http://dx.doi. org/10.1164/rccm.200407-855OC

43. Debigaré R, Marquis K, Côté C, Tremblay RR, Michaud A, LeBlanc P, et al. Catabolic/anabolic balance and muscle wasting in patients with COPD. Chest. 2003;124(1):83-9. http://dx.doi.org/10.1378/chest.124.1.83 
44. O'Donnell DE. Hyperinflation, dyspnea, and exercise intolerance in chronic obstructive pulmonary disease. Proc Am Thorac Soc. 2006;3(2):180-4. http://dx.doi. org/10.1513/pats.200508-093DO

45. Eid AA, Ionescu AA, Nixon LS, Lewis-Jenkins V, Matthews SB, Griffiths TL, et al. Inflammatory response and body composition in chronic obstructive pulmonary disease. Am J Respir Crit Care Med. 2001;164(8 Pt 1):1414-8.

46. Mador MJ. Muscle mass, not body weight, predicts outcome in patients with chronic obstructive pulmonary disease. Am J Respir Crit Care Med. 2002;166(6):787-9. http://dx.doi.org/10.1164/rccm.2206003

47. Hughson RL. Oxygen uptake kinetics: historical perspective and future directions. Appl Physiol Nutr Metab. 2009, 34:840-50. http://dx.doi.org/10.1139/ H09-088

48. Arena R, Humphrey R, Peberdy MA, Madigan M. Comparison of oxygen uptake on-kinetic calculations in heart failure. Medicine and science in sports and exercise. Oct 2002;34(10):1563-1569. http://dx.doi. org/10.1097/00005768-200210000-00006

49. Myers J, Walsh D, Sullivan M, Froelicher V. Effect of sampling on variability and plateau in oxygen uptake. J Appl Physiol. 1990;68(1):404-410.

\section{Correspondence}

\section{Bruna Varanda Pessoa}

Universidade Federal de São Carlos

Departamento de Fisioterapia

Laboratório de Espirometria e Fisioterapia Respiratória

Rod. Washington Luiz, Km 235, Monjolinho

CEP 13565-905, São Carlos, SP, Brazil

e-mail: brunavpessoa@hotmail.com 